\title{
Perfil dos Pacientes Colonizados por KPC em Internação Clínica em Hospital Terciário
}

\author{
Borges, F.K.; Moraes, T.A.; Drebes, C.V.E.; Silva, A.L.T.; Cassol, R.; Falci, \\ D.R.;
}

Apresentador: Flavia Kessler Borges

Trabalho Premiado - $2^{\circ}$ Lugar

\section{Resumo}

Introdução: A Klebsiella pneumoniae carbapenemase (KPC) vem sendo identificada em pacientes hospitalizados, principalmente internados em unidades de tratamento intensivo (UTI). Alguns estudos sugerem que a simples colonização por este germe pode estar associada ao aumento da mortalidade destes pacientes. Este estudo tem como objetivo principal avaliar o perfil epidemiológico e a mortalidade total intra-hospitalar dos pacientes clínicos colonizados por KPC no Hospital Nossa Senhora da Conceição (HNSC). Métodos: Trata-se de um estudo de coorte retrospectivo de pacientes hospitalizados, colonizados por KPC, nas unidades de internação clínica do (HNSC) entre 2012 e 2013 . Foram definidos como portadores assintomáticos, ou colonizados por KPC, aqueles pacientes clínicos com exame cultural de rastreio (swab) positivo para bactérias produtoras de KPC na internação. Resultados: Foram incluídos 75 pacientes, 40 homens, com mediana de idade de 56 [45-70] anos com escore de Charlson médio de $5+/-2$. Apenas 13 pacientes tinham internação nos últimos 3 meses. No momento da colonização por KPC 77,3\% dos pacientes estavam na UTI. O tempo desde o inicio da internação até a positivação da cultura de vigilância (swab) apresentou uma mediana de 18 dias, com período de internação longo (média 44 dias). A utilização de antibióticos pré-colonização foi elevada: penicilinas associadas com inibidores de beta-lactamase $80 \%$, carbapenêmicos $60 \%$, vancomicina $57,3 \%$ e Polimixina B 34,7\%. Considerando não apenas o uso de antibióticos pré-isolamento, mas também os outros fatores de risco para colonização, observamos uma alta prevalência também no uso de cateter de acesso central (93,3\%), sondagem vesical de demora (88\%), sondagem nasogastrica/nasoenterica $(86,7 \%)$, ventilação mecânica $(81,3 \%)$ e necessidade de hemodiálise (40\%). Mais de 70\% dos pacientes colonizados apresentaram algum processo infeccioso após a detecção de colonização. Óbito ocorreu em $56 \%$ dos pacientes $(\mathrm{n}=42)$. Conclusão: Pacientes colonizados por KPC apresentam mortalidade total intra-hospitalar elevada. O presente estudo não permite definir se esta mortalidade é atribuída à própria colonização ou se é decorrente do perfil de gravidade destes pacientes.

\section{Referência:}

Borges, F.K.; Moraes, T.A.; Drebes, C.V.E.; Silva, A.L.T.; Cassol, R.; Falci, D.R.;. Perfil dos Pacientes Colonizados por KPC em Internação Clínica em Hospital Terciário. In: II Congresso Brasileiro de Medicina Hospitalar - II CBMH [= Blucher Medical Proceedings, vol.1, num.5] São Paulo: Editora Blucher, 2014. p.2

DOI 10.5151/medpro-II-cbmh-054 